Strauss, B. S. (1956). J. gen. Microbiol. 14, 494-511

\title{
The Nature of the Lesion in the Succinate-requiring Mutants of Neurospora crassa: Interaction between Carbohydrate and Nitrogen Metabolism
}

\author{
By B. S. STRAUSS \\ Department of Zoology, Syracuse University, Syracuse 10, \\ New York, U.S.A.
}

SUMMARY: Mutants of Neurospora crassa requiring dicarboxylic acids for an immediate growth response (suc and at suc) oxidize acetate, and are inhibited by fluoroacetate with consequent citric acid accumulation to approximately the same extent as the wild-type. The concentration of nitrogen (as ammonium and nitrate salts) present in the conventional growth medium is inhibitory to the growth of these mutants and leads to an accumulation of acetylmethylcarbinol, pyruvic acid and $\alpha$-ketoisovaleric acid. This inhibition is reduced and growth is stimulated by the addition of dicarboxylic acids or by diminution of the nitrogen present in 'minimal' medium. The addition of nitrogen salts to suc mutants probably diverts dicarboxylic acids (already in short supply) from the catalysis of the oxidation of $\mathrm{C}_{2}$ fragments via the tricarboxylic acid cycle to other reactions. This effect of nitrogen salts upsets the already precarious dicarboxylic acid balance of the suc mutants leading to a growth requirement and to the accumulation of intermediates.

This investigation was begun because the existence of mutants of the ascomycete Neurospora crassa, which grow on minimal medium only after the addition of small quantities of dicarboxylic acids (succinate-requiring mutants), seemed difficult to reconcile with an apparent use of the tricarboxylic acid cycle for both synthesis and energy by Neurospora spp. (Lewis, 1948; Strauss, 1955 a). Accepting the idea of a 'genetic block' in the cyclic metabolism of dicarboxylic acids by the succinate-requiring mutants seems to require the assumption that acetate is oxidized by some mechanism other than the tricarboxylic acid cycle (Krebs, Gurin \& Eggleston, 1952) or that the 'genetic block' is not absolute. Since either of these explanations would be of interest, the properties of the succinate-requiring mutants have been studied in some detail.

It now appears that the succinate-requiring mutants do use the tricarboxylic acid cycle, and that there is no enzymic block to the operation of the cycle. Dicarboxylic acids required to catalyse acetate oxidation are in short supply and, as a result, excess ammonium or nitrate nitrogen inhibits these mutants by withdrawing this limited supply of dicarboxylic acids for synthetic purposes. Inhibition by excess nitrogen is at least partly responsible for the failure of succinate-requiring mutants to grow normally on 'minimal medium' (Beadle \& Tatum, 1945).

It is the purpose of this paper to present the evidence for the interaction of carbohydrate and nitrogen metabolism in the succinate-requiring mutants, and to discuss briefly the implications of these findings. 


\section{METHODS}

The methods used in growing Neurospora crassa have been previously described (Strauss \& Pierog, 1954; Strauss, 1955 $a$ ). Conidia were prepared by allowing cultures to grow 7 days at room temperature in the light on minimal medium with succinate $(0.5 \%$ disodium succinate) and $1.5 \%$ agar added. The conidia were harvested by being suspended in water, filtered through cheese-cloth, washed twice with water by centrifugation and finally suspended in the experimental medium as indicated below. The analytical, enzymic, isotopic and manometric methods used in this investigation were identical with those previously used, except where otherwise indicated.

\section{GENETIC MATERIALS}

Two mutations, suc and at, were used in these studies. The suc strains were derived from strain $\mathbf{4 6 0 0 5}$, a succinate-requiring mutant described by Dubes (1953) and obtained from Mrs M. B. Mitchell of the California Institute of Technology, and from strain 86, a double mutant derived as described below from one of the 'glutamate' mutants described by Woodward (1954). Both strain 46005 and Woodward's 'glutamate' mutants are phenotypically similar to the strain described by Lewis (1948) and to strain 46403 (Dubes, 1953; Strauss, $1955 a$ ); that is they grow readily with either malate, fumarate, succinate or $\alpha$-ketoglutarate and after a lag (Fig. 1) with acetate and glutamate. The two suc strains used (46005 and 86$)$ probably represent independent occurrences of the same suc mutation since: $(a)$ heterocaryons growing on minimal medium are not formed by the two strains; $(b)$ wild-type recombinants were not obtained from among 295 single ascospore cultures picked from a cross of $46005 \times 86$. The probability of not detecting a wild-type recombinant from this number of random segregants from a cross of non-allelic genes is less than $1 \%$, even if the genes are as close together as 0.8 map unit. Perithecia are formed only sparsely in this cross, and most of the resulting ascospores do not acquire the black coat characteristic of ripe spores. For our tests, spores were plated on Petri plates containing solid minimal or minimal plus succinate medium, the spores were activated and the plates were incubated at $25^{\circ}$. Only spores which had germinated within $15 \mathrm{hr}$. incubation were picked for testing.

In this paper the succinate-requiring mutants are designated suc with the wild-type allele designated $s u c^{+}$, the symbolism used by Barratt, Newmeyer, Perkins \& Garnjobst (1954). We have used absence of growth in minimal medium and response to both succinate and acetate (tested separately) as growth supplements after 3 days of incubation as a diagnostic test for the suc phenotype. The evidence that suc represents a single gene mutation is given in Table 1. Of the total of 256 ascospores tested from the type cross $s u c \times s u c^{+}$, 130 were $s u c^{+}, 126 s u c$, a close fit to the expected 1:1 ratio.

Strain 86 was obtained by the method of Woodward, De Zeeuw \& Srb (1954), starting with a 'glutamic' mutant obtained by Dr Woodward from wild-type 
74 A by X-irradiation. Further X-irradiation of the conidia of this mutant followed by incubation with shaking in minimal medium plus glutamate resulted after repeated filtration in the isolation of a strain which differed phenotypically from the original. This new strain (86), obtained in the course of work at Brookhaven National Laboratory, did not grow within 3 days on either acetate or glutamate supplements, although it still responded to either

Table 1

\begin{tabular}{|c|c|c|c|c|c|c|}
\hline & & 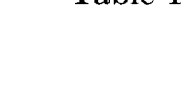 & Total seg & gregants & No. of & $\begin{array}{l}\text { Percen- } \\
\text { tage } \\
\text { second }\end{array}$ \\
\hline $\begin{array}{l}\text { Parental } \\
\text { strains }\end{array}$ & $\begin{array}{l}\text { Presumed } \\
\text { parental } \\
\text { genotypes }\end{array}$ & $\begin{array}{c}\text { Phenotypes } \\
\text { of } \\
\text { segregants }\end{array}$ & Random & $\begin{array}{c}\text { From } \\
\text { ordered } \\
\text { asci }\end{array}$ & $\begin{array}{c}\text { classifiable } \\
\text { asci for gene } \\
\text { indicated }\end{array}$ & $\begin{array}{c}\text { division } \\
\text { segre- } \\
\text { gation }\end{array}$ \\
\hline $46005 \times 8 a$ & $\begin{array}{c}a t^{+} s u c \\
\times \\
a t^{+} s u c^{+}\end{array}$ & $\begin{array}{l}a t^{+} s u c \\
a t^{+} s u c^{+}\end{array}$ & - & $\left.\begin{array}{l}31 \\
43\end{array}\right\}$ & $18(s u c)$ & 11 \\
\hline $15300 \times 46005$ & $\begin{array}{c}a l b a t^{+} s u c^{+} \\
\times \\
a l b^{+} a t^{+} s u c\end{array}$ & $\begin{array}{l}\text { alb } a t^{+} s u c^{+} \\
a l b^{+} a t^{+} s u c \\
a l b a t^{+} s u c \\
a l b^{+} a t^{+} s u c^{+}\end{array}$ & $\begin{array}{r}21 \\
32 \\
8 \\
16\end{array}$ & $\left.\begin{array}{l}30 \\
23 \\
32 \\
20\end{array}\right\}$ & $\begin{array}{l}12(a l b) \\
12(s u c)\end{array}$ & $\begin{array}{l}50 \\
42\end{array}$ \\
\hline $86 \times 15300$ & $\begin{array}{c}a l b^{+} a t s u c \\
\times \\
a l b a t^{+} s u c^{+}\end{array}$ & $\begin{array}{l}a l b^{+} a t^{+} s u c^{+*} \\
\text { alb at } \text { t }^{+} u c^{+*} \\
\text { alb at suc } \\
\text { alb at } t^{+} s u c \\
a l b^{+} \text {at suc } \\
a l b^{+} a t^{+} s u c\end{array}$ & $\begin{array}{l}- \\
- \\
-\end{array}$ & $\left.\begin{array}{l}30 \\
70 \\
16 \\
33 \\
22 \\
42\end{array}\right\}$ & $\begin{array}{r}16(a l b) \\
16(s u c) \\
8(a t)\end{array}$ & $\begin{array}{r}75 \\
16 \\
0\end{array}$ \\
\hline $86 \times 5297$ & $\begin{array}{c}a t \text { suc } \\
\times \\
a t^{+} s u c^{+}\end{array}$ & $\begin{array}{l}a t^{+} s u c^{+*} \\
a t^{+} s u c \\
\text { at suc }\end{array}$ & - & $\left.\begin{array}{r}27 \\
14 \\
7\end{array}\right\}$ & $\begin{array}{l}4(s u c) \\
4(a t)\end{array}$ & $\begin{array}{l}0 \\
0\end{array}$ \\
\hline $27-1 \dagger \times 46005$ & $\begin{array}{r}a t s u c^{+} \\
\times \\
a t^{+} \operatorname{suc}\end{array}$ & $\begin{array}{l}a t^{+} s u c^{+*} \\
a t^{+} s u c \\
\text { at suc }\end{array}$ & - & $\left.\begin{array}{l}36 \\
23 \\
18\end{array}\right\}$ & $\begin{array}{l}10(s u c) \\
10(a t)\end{array}$ & $\begin{array}{l}0 \\
0\end{array}$ \\
\hline
\end{tabular}

Phenotypes: $a l b=$ albino; colourless mycelium. $a l b^{+}=$wild type coloration. $a t^{+}$ $s u c=s u c=$ no growth in 3 days on minimal medium; growth with succinate or acetate added as supplements. at suc=no growth in 3 days on minimal medium or on minimal + acetate; growth on minimal + succinate. $a t^{+} s u c^{+}=$wild type =growth on minimal medium.

* The $a^{+} s u c^{+}$phenotype includes the class of $a t s u c^{+}$strains since these grow on minimal medium (see Table 2).

$\dagger$ See Table 2 for the origin of this strain.

succinate, fumarate, malate or $\alpha$-ketoglutarate. The new strain obtained was crossed to wild-type and a high conidiating segregant (86-1) was obtained. The evidence that strain $86-1$ is a double mutant is summarized in Table 1 . Crosses of 86-1 to wild-type or to the morphological mutant, albino, give asci-yielding nutritional mutants of parent type (no growth on acetate) and recombinants (mutants growing on acetate) with spore pairs always giving the same results. Furthermore, a supposed $a t s u c^{+}$strain selected from ascus \#27 of the cross $86 \times 5297$ (Table 2 ), when crossed to strain 46005 (supposed $a t^{+} s u c$ ) gave asci containing spores yielding cultures with at suc phenotypes, as would be expected if this cross $(27-1 \times 46005)$ were at suc $c^{+} a t^{+} s u c$. On totalling the data in Table 1 it will be noted that a total of $112 a t^{+} s u c$ strains were obtained 
from the type cross at suc $\times a t^{+}$suc compared to a total of 63 at suc. We believe that this discrepancy from the expected $1: 1$ ratio probably is due to the relatively low percentage germination of at suc ascospores compared to $a t^{+} s u c$ spores for which we have other evidence. No classifiable ascus has been obtained that is not in accord with the hypothesis of a single modifier gene. This gene was designated $a t$ to indicate its effect on the utilization of acetate, and to distinguish it from the acetate requiring mutants described earlier under the designation ac (Strauss \& Pierog, 1954). The at locus apparently acts only as a modifier to the suc gene, preventing response of suc strains to acetate. In the presence of the wild-type allele of suc, the at gene apparently has no effect since strain 27-1 $\left(a t s u c^{+}\right)$grows normally on minimal medium.

Table 2. Composition of ascus 27

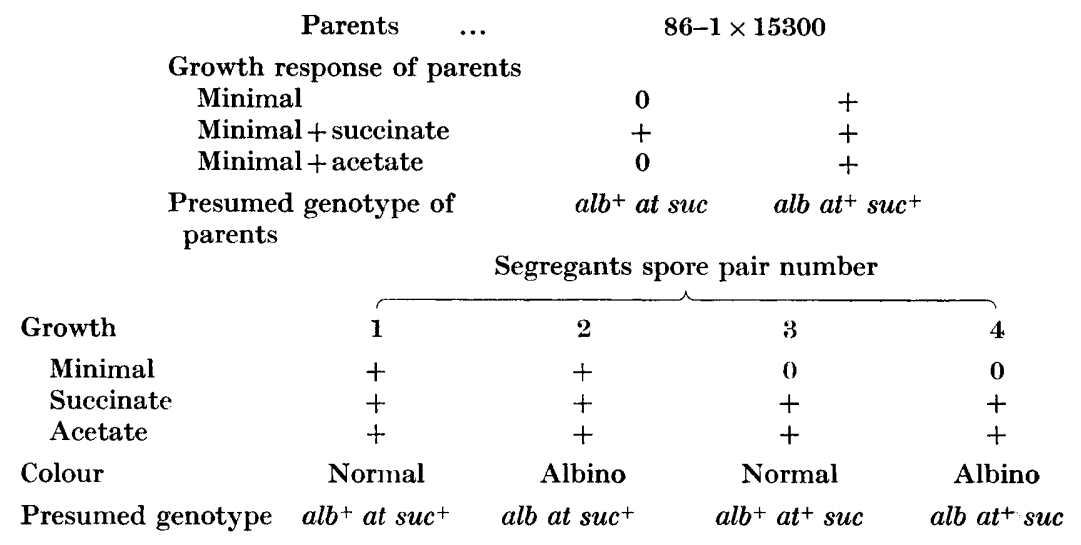

RESULTS

Growth studies

Both suc and at suc strains grow well in the presence of succinate (Figs. 1, 2), suc grows on acetate and on glutamate after a short lag, while the at suc strain grows on acetate only after a considerable lag period. At about the same time that at suc strains show visible growth with an acetate supplement, suc strains initiate growth on minimal, and the growth of suc on minimal roughly parallels the growth of at suc on acetate. The suc mutants are not permanently adapted after initiation of growth on minimal medium since subinoculations of cultures that are growing on minimal medium on to fresh minimal medium require a long lag period before again starting to grow. As can be seen from the scatter of points in Fig. 1, the time at which cultures of suc on minimal medium or of at suc on acetate begin to grow rapidly varies noticeably from flask to flask.

When cultures are grown with varying amounts of nitrogen (added as ammonium sulphate and substituting equimolar amounts of sodium potassium tartrate for the ammonium tartrate usually present) there is an inhibition of mutant growth by quantities of nitrogen that do not inhibit the wild-type (Fig. 3). This inhibition is counteracted by the addition of succinate (Table 3). 


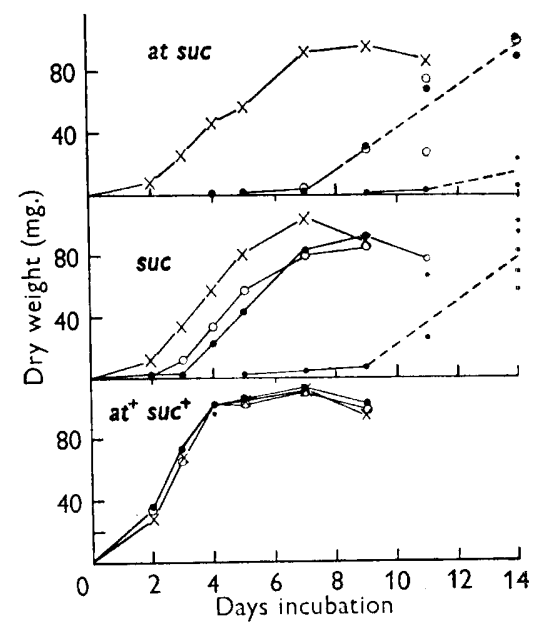

Fig. 1

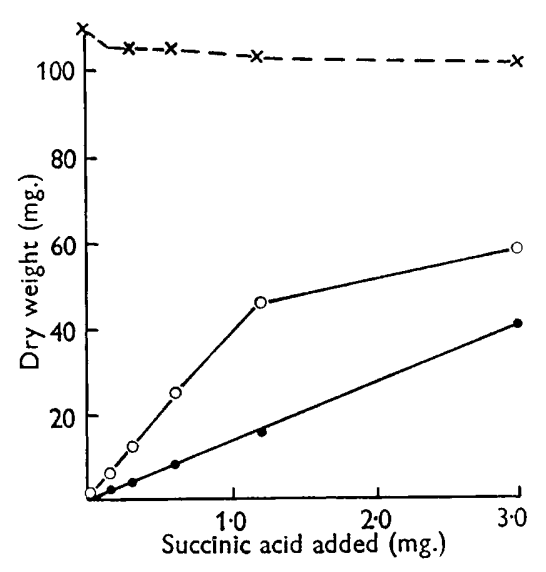

Fig. 2

Fig. 1. Growth of suc mutants as a function of time. Additions to $20 \mathrm{ml}$. minimal medium: $25 \mu \mathrm{M}$ succinic acid or glutamic acid as sodium salts. $50 \mu \mathrm{m}$ acetic acid as the sodium salt: $\times$, succinate added; $\bigcirc$, acetate added; $\bullet$, glutamate added; $\bullet$, no addition.

Fig. 2. Growth of at suc and suc strains as a function of succinate concentration. Growth after 4 days at $28^{\circ}$. Succinic acid added as disodium salt: $\times, 7 \mathrm{~A}\left(a t^{+} s u c^{+}\right)$; $\mathrm{O}$, 46005 (suc); 0,86 (at suc).

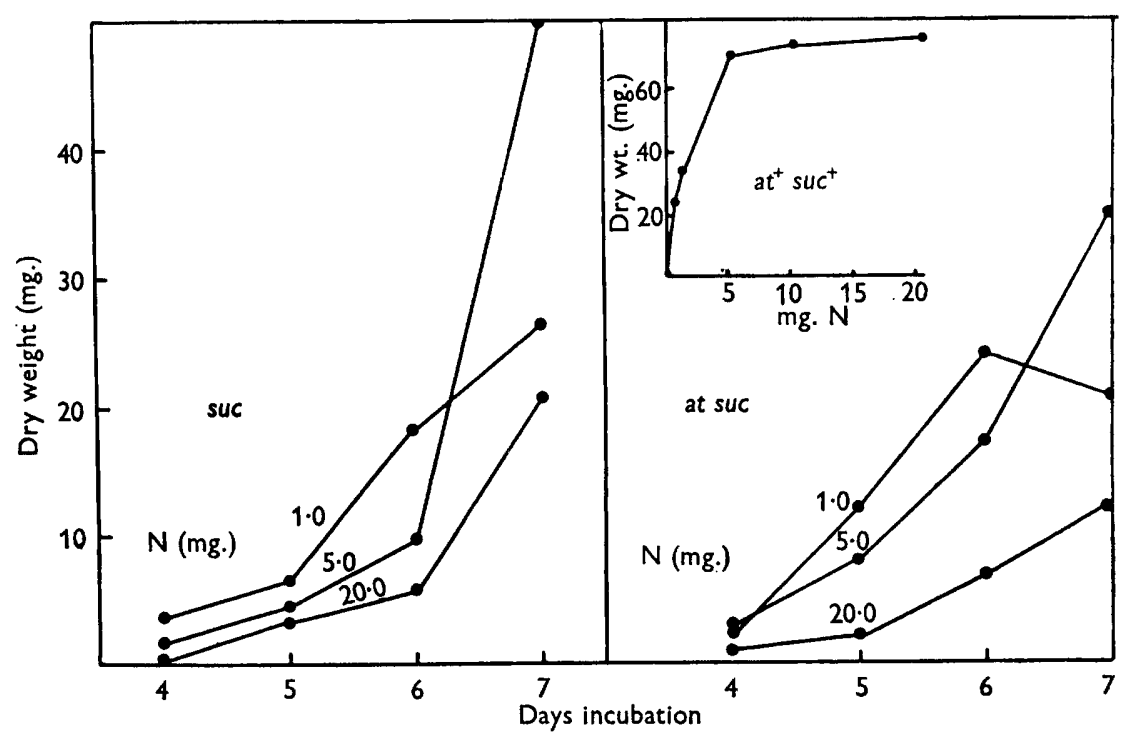

Fig. 3. Effect of nitrogen concentration on growth of suc. Wild-type curve of growth as a function of nitrogen concentration obtained after 3 days' incubation. suc grown with no organic supplement. at suc grown with $5 \mathrm{mg}$. $\mathrm{Na}_{2} \mathrm{C}_{2} \mathrm{H}_{3} \mathrm{O}_{2} \cdot 3 \mathrm{H}_{2} \mathrm{O}$ per $20 \mathrm{ml}$. Nitrogen added as $\left(\mathrm{NH}_{4}\right)_{2} \mathrm{SO}_{4}$. 
Both suc and at suc strains are inhibited by the amount of nitrogen ordinarily present in minimal medium $(22 \cdot 2 \mathrm{mg} . / 20 \mathrm{ml}$. as ammonium tartrate and ammonium nitrate).

\section{Accumulations}

The suc strains accumulate acetylmethylcarbinol (AMC, 3-hydroxy-2butanone), pyruvic acid and $\alpha$-ketoisovaleric acid when grown on limiting succinate concentrations. AMC was first recognized by its characteristic odour and by the Voges-Proskauer reaction (Westerfeld, 1945) given by steam distillates of culture medium. It was identified in the steam distillate from suc culture medium by the formation of the characteristic precipitate of nickel dimethylglyoxime after oxidation (of the steam distillate) with $\mathrm{FeCl}_{3}$ in acid, with subsequent distillation of the oxidation product into neutralized hydroxylamine in the presence of nickel chloride and sodium acetate. This compound (AMC) has been previously identified as an accumulation product of neurospora mutants requiring acetate for growth (Strauss, 1953).

Table 3. Effect of succinic acid on the inhibition of the growth of a suc strain by ammonium nitrogen

\begin{tabular}{|c|c|c|c|c|c|c|}
\hline \multirow{2}{*}{$\begin{array}{c}\text { Succinic } \\
\text { acid } \\
\text { (mg./flask) }\end{array}$} & \multicolumn{5}{|c|}{ mg. $N$ per flask } & \multirow[b]{2}{*}{ Strain } \\
\hline & 0.5 & $1 \cdot 0$ & $\mathbf{2} \cdot \mathbf{0}$ & $8 \cdot 0$ & $25 \cdot 0$ & \\
\hline 0 & 12 & 13 & 9 & 4 & 2 & $s u c(46005)$ \\
\hline 0.6 & 22 & 31 & 37 & 30 & 21 & \\
\hline $1 \cdot 2$ & 25 & 39 & 45 & 41 & 42 & \\
\hline 0 & 22 & 35 & 50 & 105 & 103 & $s u c^{+}(7 \mathrm{~A})$ \\
\hline
\end{tabular}

Recorded growth as mg. dry wt. after 4 days at $25^{\circ}$ in medium using sodium potassiumtartrate. Nitrogen added as ammonium sulphate. Succinic acid added as disodium succinate. Values averages of duplicates.

Accumulation of keto acids in culture media in which suc strains had grown was indicated by the formation of 2,4-dinitrophenylhydrazine derivatives which could be extracted from ethyl acetate by sodium carbonate and then returned to an ethyl acetate layer after acidification. Pyruvic acid was identified by chromatography as one of the accumulation products of the dinitrophenylhydrazones after two passages through sodium carbonate; a spot coincided with that given by an authentic sample of pyruvic 2,4-dinitrophenylhydrazone after ascending chromatography in tertiary amyl alcohol : ethanol : water $(50: 10: 40)$ or in isobutanol : water $(90: 10)$. Another major spot (distinct from the second spot given by the pyruvic acid derivatives) was noted with an $\boldsymbol{R}_{f}$ of $\mathbf{0 . 8 3}$ in the tertiary amyl alcohol mixture and with an $\boldsymbol{R}_{f}$ of $\mathbf{0 . 5}$ in isobutanol : water. These $\boldsymbol{R}_{\boldsymbol{f}}$ values, higher than those characteristic of pyruvic acid, indicate a compound with more non-polar character than pyruvic acid. We have provisionally identified this compound as the derivative of $\alpha$-ketoisovaleric acid since the unknown compound gave a spot which was superimposed on the spot given by the 2,4-dinitrophenylhydrazine derivative of an authentic sample of $\alpha$-ketoisovaleric acid (kindly 
provided by Dr H. E. Umbarger) after chromatography with either the tertiary amyl alcohol mixture or with isobutanol : water.

Cultures of the suc strain grown in the presence of succinate show a steadily decreasing accumulation of AMC as growth proceeds (Fig. 4). In the absence of succinate relatively more AMC is accumulated up to the point where rapid growth begins. Nitrogen (added as ammonium sulphate) leads to an increase in the amount of AMC accumulated per mg. dry weight (Table 4), whereas succinate reduces the amount of accumulation.

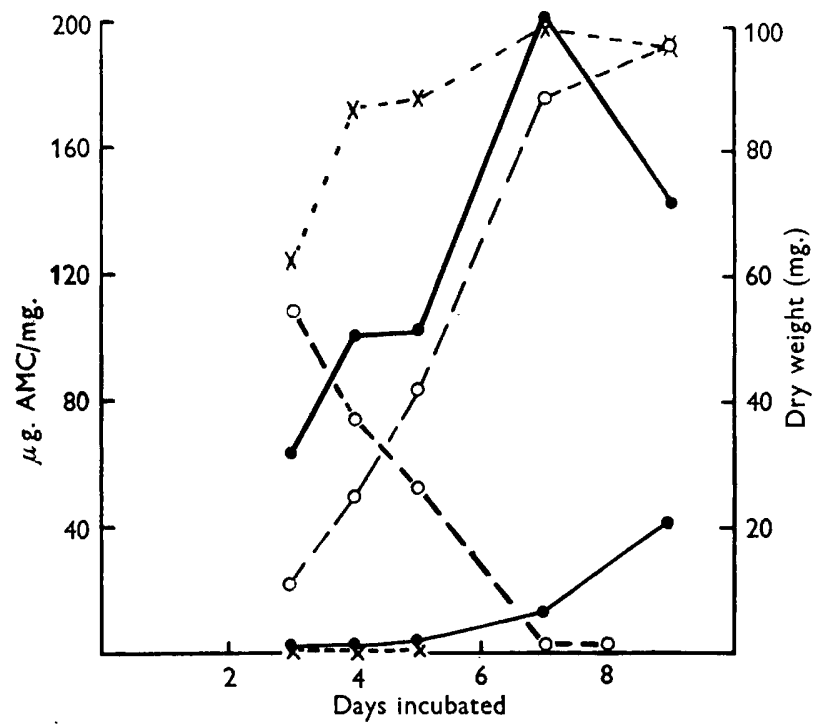

Fig. 4. Amount of acetylmethylcarbinol accumulated by suc cultures as a function of time and the presence of succinic acid. Succinic acid $=1.2 \mathrm{mg}$. $/$ lask added as disodium succinate. Lighter lines show dry weight produced. suc plus succinate; $\times \ldots .-\times, 7 \mathrm{~A}\left(s u c^{+}\right)$no succinate.

Table 4. Effect of succinic acid and ammonium nitrogen on the accumulation of acetylmethylcarbinol by a suc mutant Succinic acid
(mg./flask)

0

$\mathbf{0} \cdot \mathbf{3}$

$1 \cdot 2$

3.0 mg. $\mathbf{N}$ per flask

\begin{tabular}{|c|c|c|c|}
\hline 1.0 & $5 \cdot 0$ & $10 \cdot 0$ & $20 \cdot 0$ \\
\hline $\begin{array}{r}329 \\
(4)\end{array}$ & - & - & - \\
\hline $\begin{array}{c}109 \\
(19)\end{array}$ & $\begin{array}{c}179 \\
(20)\end{array}$ & $\begin{array}{c}183 \\
(14)\end{array}$ & $\begin{array}{l}224 \\
(12)\end{array}$ \\
\hline $\begin{array}{c}15 \\
(33)\end{array}$ & - & - & - \\
\hline 1 & - & - & - \\
\hline
\end{tabular}

(33)

Cultures grown 4 days in medium containing sodium potassium tartrate as a substitute for ammonium tartrate.

Nitrogen added as ammonium sulphate. Succinic acid added as disodium succinate.

AMC vaues as $\mu \mathrm{g}$. accumulated/mg. dry weight. Values averages of duplicate flasks. Dry weight given in parentheses. 
There is a reciprocal relationship between AMC accumulation and germination of the suc and at suc mutants. Conidia incubated in phosphate buffer with sucrose send out long germ tubes, and if the conidial suspension is dense enough there is visible growth after a $\mathbf{2 3} \mathrm{hr}$. shaking period. Nitrogen salts completely inhibit the germination of at suc conidia, greatly reduce the germination of suc conidia, and cause the accumulation of AMC by both suc and at suc mutants

Table 5. Effects of the constituents of minimal medium on germination and acetylmethylcarbinol accumulation

\begin{tabular}{|c|c|c|c|c|c|c|}
\hline \multirow[b]{2}{*}{ Addition } & \multicolumn{2}{|c|}{ Strain $7 \mathrm{~A}\left(a t^{+} s u c^{+}\right)$} & \multicolumn{2}{|c|}{ Strain $46005\left(a t^{+} s u c\right)$} & \multicolumn{2}{|c|}{ Strain 86 (at suc) } \\
\hline & $\mathbf{A M C}$ & Germination & AMC & Germination & AMC & Germination \\
\hline None & 0 & $\begin{array}{c}\text { Small clumps } \\
\text { of mycelium }\end{array}$ & $\mathbf{0}$ & $\begin{array}{l}\text { Germination } \\
\text { with long } \\
\text { germ tubes. } \\
\text { Some clumps }\end{array}$ & 0 & $\begin{array}{l}\text { Good germina- } \\
\text { tion with long } \\
\text { germ tubes }\end{array}$ \\
\hline $\begin{array}{l}0.5 \% \text { ammonium } \\
\text { tartrate }\end{array}$ & 0 & $\begin{array}{l}\text { Germination } \\
\text { but no } \\
\text { clumps }\end{array}$ & 38 & $\begin{array}{c}\text { Some germina- } \\
\text { tion but many } \\
\text { non-germina- } \\
\text { ted conidia }\end{array}$ & 19 & $\begin{array}{l}\text { Practically no } \\
\text { germination } \\
\text { of conidia }\end{array}$ \\
\hline $0.05 \% \mathrm{Mg} \mathrm{SO}_{4} .7 \mathrm{H}_{2} \mathrm{O}$ & 0 & $\begin{array}{l}\text { Clumps of } \\
\text { mycelium }\end{array}$ & 0 & $\begin{array}{l}\text { Heavy my- } \\
\text { celial clumps } \\
\text { formed }\end{array}$ & 0.5 & $\begin{array}{l}\text { Germination } \\
\text { with much } \\
\text { mycelial } \\
\text { development }\end{array}$ \\
\hline $\begin{array}{l}0.01 \% \mathrm{NaCl}, \\
0.01 \% \mathrm{CaCl}_{2} \text { trace } \\
\text { elements and } \\
\text { biotin* }\end{array}$ & $\mathbf{0}$ & $\begin{array}{l}\text { Clumps of } \\
\text { mycelium }\end{array}$ & $\mathbf{0}$ & $\begin{array}{l}\text { Very heavy } \\
\text { clumps of } \\
\text { mycelium } \\
\text { formed }\end{array}$ & 0 & $\begin{array}{l}\text { Clumps of } \\
\text { mycelium }\end{array}$ \\
\hline $0.5 \% \mathrm{KNO}_{3}$ & 0 & $\begin{array}{l}\text { Germination } \\
\text { with small } \\
\text { germ tubes } \\
\text { and no } \\
\text { clumps }\end{array}$ & 25 & $\begin{array}{l}\text { Good germina- } \\
\text { tion but some } \\
\text { non-germina- } \\
\text { ted conidia }\end{array}$ & 20 & $\begin{array}{l}\text { No germina- } \\
\text { tion }\end{array}$ \\
\hline
\end{tabular}

AMC as total $\mu \mathrm{g}$. accumulated after $23 \mathrm{hr}$. shaking at $28^{\circ}$ determined by direct analysis of the medium after removal of conidia by centrifugation.

Added $4.7 \times 10^{7}$ suc, $1.1 \times 10^{8}$ at suc and $9.8 \times 10^{7} a^{+} s^{+} c^{+}(7 \mathrm{~A})$ conidia to $54 \mathrm{ml}$. of $0.067 \mathrm{M}$-phosphate buffer $\mathrm{pH} 6.0$ plus $2 \%$ sucrose plus additions as shown. The conidia were harvested from 7 -day cultures and washed three times with water by centrifugation before use.

* Trace elements and biotin added as in minimal medium.

('Table 5). Conidia of the suc and at suc strains suspended in minimal medium and shaken 2-4 hr. in manometer vessels at $30^{\circ}$ accumulate measurable amounts of AMC. No accumulation is noted when conidia of these strains are shaken under identical conditions with $2 \%$ sucrose in phosphate buffer $(0.067 \mathrm{M}, \mathrm{pH} 6.0)$, although sucrose in phosphate buffer is rapidly oxidized by both suc and at suc strains.

\section{Oxidation studies}

The wild-type, suc and at suc strains oxidize sucrose and acetate readily with no appreciable time lag (Fig. 5). There are no appreciable differences in the rate of mutant and wild-type oxidation. Sodium fluoroacetate inhibits acetate 
oxidation by both wild-type and mutant strains (Table 6), with a concomitant increase in the accumulation of citrate (Table 7 ) as determined by the method of Ettinger, Goldbaum \& Smith (1952). Although the data are given for conidia (because of the greater uniformity of this material) suc and at suc oxidation of acetate and sucrose, inhibition by fluoroacetate and accumulation of citrate can be readily demonstrated with mycelium from $24 \mathrm{hr}$. shake cultures.

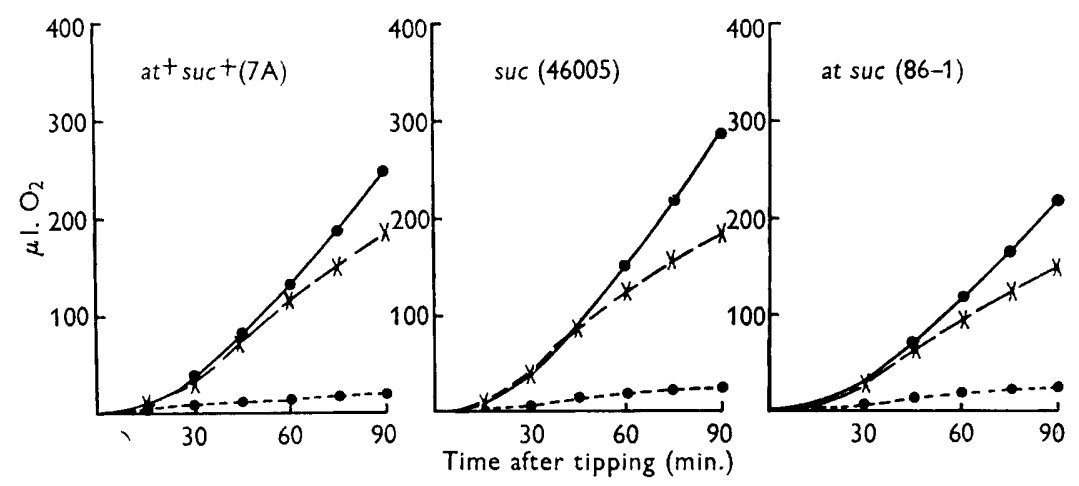

Fig. 5. Oxidation of acetate and sucrose by suc and at suc. Oxygen consumption measured at $30^{\circ}$. Reaction mixture contained $2 \mathrm{ml}$. conidial suspension $+0 \cdot 3 \mathrm{ml}$. substrate in $0.067 \mathrm{M}-\mathrm{KH}_{2} \mathrm{PO}_{4}-\mathrm{Na}_{2} \mathrm{HPO}_{4}$ buffer, $\mathrm{pH} \mathrm{6} \cdot 0$. - - - , endogenous; $-\longrightarrow$, acetate, $\times--x$, sucrose.

Table 6. Inhibition of acetate oxidation by sodium fluoroacetate

\begin{tabular}{|c|c|c|c|c|}
\hline \multirow[b]{2}{*}{ Strain } & \multicolumn{4}{|c|}{ Addition } \\
\hline & None & $\begin{array}{c}\text { Sodium } \\
\text { acetate, } \\
10 \mu \mathrm{M}\end{array}$ & $\begin{array}{c}\text { Sodium } \\
\text { fluoroacetate, } \\
20 \mu_{\mathrm{M}}\end{array}$ & $\begin{array}{c}\text { Sodium acetate } \\
\text { plus sodium } \\
\text { fluoroacetate }\end{array}$ \\
\hline at suc & 24 & 202 & 8 & 25 \\
\hline suc & 28 & 233 & 9 & 29 \\
\hline $7 \mathrm{~A}\left(a t^{+} s u c^{+}\right)$ & 17 & 194 & 5 & 20 \\
\hline
\end{tabular}

Recorded $\mu \mathrm{l} . \mathrm{O}_{2}$ taken up in the first $90 \mathrm{~min}$. after tipping. Final volume in the main compartment $=\mathbf{2} \cdot \mathbf{5} \mathrm{ml}$.

Added suspensions of conidia grown 7 days and washed twice with water, once with buffer after harvesting. Suspensions made up to approximately the same turbidity in $0.067 \mathrm{M}$-phosphate buffer pH $6 \cdot 0$. Two ml. of conidial suspensions added to each vessel.

It is possible to demonstrate an active isocitric-dehydrogenase and glutamicdehydrogenase in extracts of suc and at suc prepared and tested by a method similar to that used by Fincham (1954). Extracts of at suc prepared from material grown 2 days in shake culture on minimal medium plus succinate contain an active glutamic-dehydrogenase, even though these strains do not show significant amounts of growth with glutamate as a growth supplement before the end of a 7-day lag period (Fig. 6). $\alpha$-Ketoglutaric acid, sterilized by filtration, produces a growth response by at suc as rapidly as does succinate. Although glutamate does not initiate growth within the first 3 days, it does 
stimulate growth in this time period in the presence of a limiting amount of succinate (Table 8 ).

Yemm \& Folkes (1954) showed that nitrogen-deficient cultures of Torulopsis utilis, suspended under aerobic conditions in a carbohydrate-free medium, doubled or tripled their rate of oxygen uptake on the addition of ammonium nitrogen. Since this appeared to be a method of studying the systems of
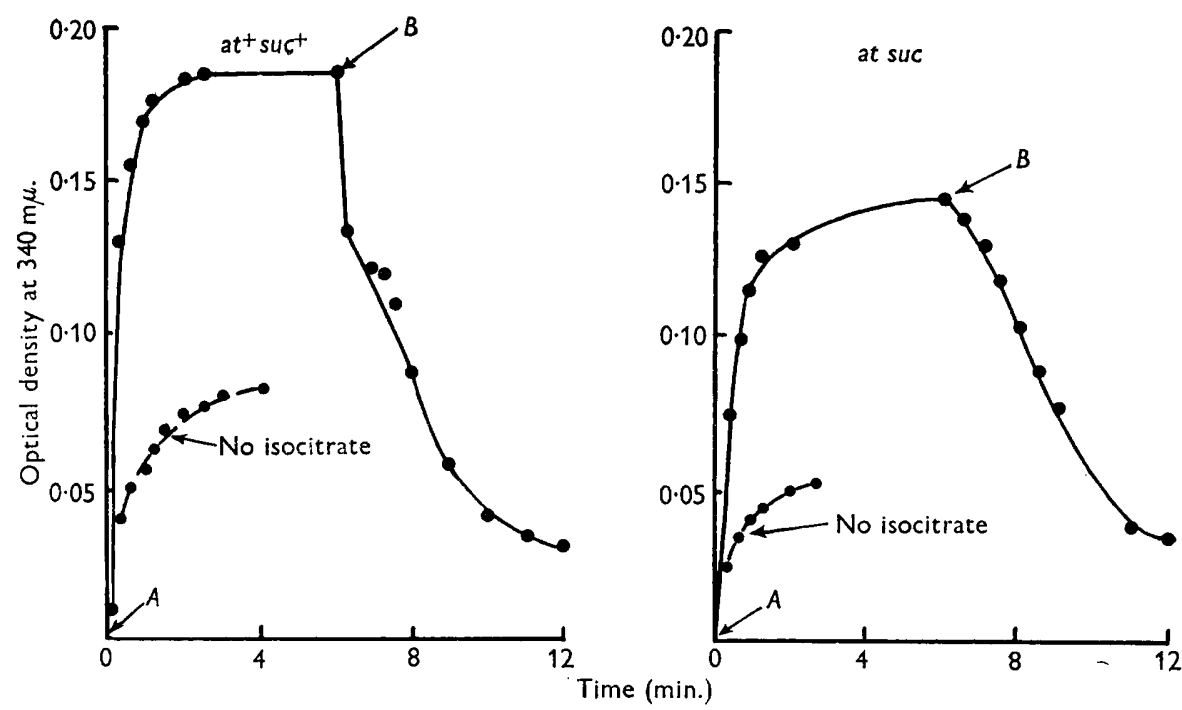

Fig. 6. Presence of glutamic dehydrogenase in an at suc strain. Reaction mixtures: isocitrate $400 \mu \mathrm{g}$., $0 \cdot 6 \mathrm{ml} .0 \cdot 05 \mathrm{M}$-tris(hydroxymethyl)aminomethane buffer $\mathbf{p H ~} 7 \cdot 2,0 \cdot 1 \mathrm{ml}$. $0.02 \mathrm{M}-\mathrm{MnCl}_{2}, 50 \mu \mathrm{g}$. TPN (Sigma Chemical Company), $0.1 \mathrm{ml}$. enzyme extract. Total volume $=3 \mathrm{ml}$. Dotted line without isocitrate. Added TPN at arrow $A$. At arrow $B$ added $5 \mu \mathrm{M}-\alpha$-ketoglutarate, $10 \mu \mathrm{M}-\mathrm{NH}_{4} \mathrm{Cl}$. Enzyme extracted from 2-day shake cultures grown in minimal medium with succinate, collected, washed, ground with alumina in $0.05 \mathrm{M}-\mathrm{KH}_{2} \mathrm{PO}_{4}-\mathrm{Na}_{2} \mathrm{HPO}_{4}$ buffer $\mathrm{pH} 7 \cdot 2$ and centrifuged in the cold at $11,000 \mathrm{~g}$ for $20 \mathrm{~min}$. Supernatent used as enzyme preparation.

Table 7. Accumulation of citric acid in the presence of sodium fluoroacetate

$\begin{array}{ccccc}\text { Strain } & \overbrace{4}^{\text {Sodium acetate, }} & \begin{array}{c}\text { Sodium fluoro- } \\ \text { acetate, 50 } \mu \mathrm{M}\end{array} & \begin{array}{c}\text { Acetate plus } \\ \text { fluoroacetate }\end{array} \\ \text { suc }(46005) & \text { None } & 100 \mu \mathrm{M} & 93 & 160 \\ & 64 & 98 & 120 & 190 \\ s u c^{+}(7 \mathrm{~A}) & - & 89 & 110 & 170 \\ & 32 & 57 & 92 & 130\end{array}$

Recorded total $\mu \mathrm{g}$. of citric acid accumulated in a total volume of $2.5 \mathrm{ml}$. Added $3.4 \times 10^{8} s u c^{+}$conidia, $3,7 \times 10^{8} s u c$ conidia. Citric acid extracted and reaction stopped after two hours' incubation at $30^{\circ}$ with shaking by heating in a boiling water bath with $0.5 \mathrm{ml}$. $9 \mathrm{~N}-\mathrm{H}_{2} \mathrm{SO}_{4}$ and diluting to $10 \mathrm{ml}$.

carbohydrate metabolism under conditions of maximum utilization, an experiment similar to, but not identical with, that of Yemm \& Folkes was performed. Conidia of the various strains were prepared as usual and washed 
Table 8. Stimulation of growth of at suc by glutamate in the presence of limiting concentrations of succinate

\begin{tabular}{crrrrr}
$\begin{array}{c}\text { Disodium } \\
\text { succinate }\end{array}$ & \multicolumn{4}{c}{ Monosodium glutamate (mg./flask) } \\
(mg./flask) & 0 & 1 & 2 & 4 & 8 \\
0 & 0 & 0 & 0 & $0 \cdot 2$ & $0 \cdot 8$ \\
1 & 5 & 7 & 8 & 10 & 25 \\
2 & 13 & 10 & 18 & 26 & 39 \\
4 & 21 & 28 & 32 & 37 & 46 \\
8 & 32 & 43 & 43 & 46 & 54
\end{tabular}

Recorded mg. dry weight produced by at suc (86-1 A) after 3 days in minimal medium plus additions as shown. All values averages of duplicate determinations.

Table 9. Effect of nitrogen on oxygen uptake by suc conidia incubated with sucrose

\begin{tabular}{|c|c|c|c|c|c|c|}
\hline \multirow{3}{*}{ Expt. no. } & \multirow[b]{2}{*}{$\begin{array}{l}\text { Preincuba- } \\
\text { tion period } \\
\text { (hr.) }\end{array}$} & \multicolumn{4}{|c|}{ Strain } & \multirow[b]{2}{*}{$\begin{array}{l}\text { Time after } \\
\text { tipping }\end{array}$} \\
\hline & & Nitrogen & $\begin{array}{c}a t^{+} s u c^{+} \\
(7 \mathrm{~A})\end{array}$ & $\underbrace{s(46005)}_{s u c}$ & $\begin{array}{c}\text { at suc } \\
(86)\end{array}$ & \\
\hline & \multirow[t]{4}{*}{1} & 0 & 351 & 239 & 374 & \multirow{4}{*}{105 min. } \\
\hline & & & 359 & 232 & 375 & \\
\hline & & + & 450 & 172 & 284 & \\
\hline & & & 445 & 182 & $287)$ & \\
\hline & \multirow[t]{4}{*}{24} & 0 & 130 & 246 & $137)$ & \multirow{4}{*}{$120 \mathrm{~min}}$. \\
\hline & & & 114 & 183 & 145 & \\
\hline & & + & 201 & 247 & 144 & \\
\hline & & & 176 & 210 & 171 J & \\
\hline \multirow[t]{8}{*}{2} & \multirow[t]{4}{*}{1} & 0 & 318 & 251 & 257 & \multirow{4}{*}{$120 \mathrm{~min}}$. \\
\hline & & & 365 & 244 & -1 & \\
\hline & & + & 533 & 211 & 184 & \\
\hline & & & 531 & 215 & 169 & \\
\hline & \multirow[t]{4}{*}{24} & 0 & 136 & 65 & 136 & \multirow{4}{*}{$120 \mathrm{~min}}$. \\
\hline & & & 135 & 54 & 134 & \\
\hline & & \multirow[t]{2}{*}{+} & 254 & 74 & 208 & \\
\hline & & & 248 & 73 & 181 & \\
\hline
\end{tabular}

Conidia grown 7 days. Harvested and washed twice with water by centrifugation. Suspended in buffer as described in text.

$2 \mathrm{ml}$. suspension added to flask. Side arm contained either $0.2 \mathrm{ml}$. of water or $0.2 \mathrm{ml}$. of a solution containing $2.75 \mathrm{mg}$. N/ml. $\left(\right.$ as $\left(\mathrm{NH}_{4}\right)_{2} \mathrm{SO}_{4}$ ) as indicated. $0.067 \mathrm{M}-\mathrm{KH}_{2} \mathrm{PO}_{4}-\mathrm{Na}_{2} \mathrm{HPO}_{4}$ buffer $\mathrm{pH} 6 \cdot 0,2 \%$ sucrose plus $0.05 \% \mathrm{MgSO}_{4} \cdot 7 \mathrm{H}_{2} \mathrm{O}$. Recorded total $\mu \mathrm{I} . \mathrm{O}_{2}$ taken up in the indicated time interval.

with 0.067 M-phosphate buffer $\mathrm{pH} 6.0$ containing $2 \%$ sucrose and $0.05 \%$ $\mathrm{MgSO}_{4} \cdot{ }_{7} \mathrm{H}_{2} \mathrm{O}$. One set of conidia of each strain was suspended in this buffer $1 \mathrm{hr}$., and after resuspending in fresh buffer of identical composition, $2 \mathrm{ml}$. of this conidial suspension were placed in a manometric vessel containing ammonium sulphate in the side arm (Table 7). The second set of conidia was shaken for $24 \mathrm{hr}$. in the sugar-containing buffer, then the germinated conidia were strained through cheese-cloth, resuspended in fresh sugar-containing buffer and treated in a manner similar to the conidia of set 1 (Table 9). In these experiments the turbidity of the conidial suspensions of set 1 was 
adjusted so that approximately the same number of wild-type, suc and at suc, conidia were added to the manometers. The suspensions after shaking for $24 \mathrm{hr}$. were not adjusted in this manner.

The addition of ammonium nitrogen to a 'fresh' conidial suspension results in a stimulation of oxygen uptake by wild-type conidia in a manner reminiscent of the Yemm \& Folkes phenomenon, but the addition of ammonium nitrogen depresses the uptake of oxygen by mutant conidia. After $24 \mathrm{hr}$. shaking in the absence of nitrogen, however, even mutant conidia are slightly stimulated by the addition of nitrogen, although not as much as the wild-type.

\section{Carbon dioxide fixation}

The different effect of ammonium on the oxygen uptake of $s u c$ and $s u c^{+}$ prompted us to look for the mechanisms that might supply dicarboxylic acids for interaction with ammonium. Since carbon dioxide fixation is one mechanism for the net synthesis of dicarboxylic acids (Utter \& Wood, 1951) it was decided to measure the amount of carbon dioxide fixation by wild-type and suc strains. Conidia prepared by the methods used to study the effect of nitrogen on oxygen uptake (cf. above) were incubated with $0 \cdot 2 \mu \mathrm{c} . \mathrm{NaH}^{14} \mathrm{CO}_{3}$ in closed manometer vessels in the presence and absence of ammonium nitrogen. At the conclusion of a $2 \mathrm{hr}$. shaking period the conidia were harvested by centrifugation, washed twice with unlabelled $0 \cdot 1 \mathrm{M}-\mathrm{NaHCO}_{3}$ and twice with hot water. The conidial suspensions were then transferred to stainless steel planchets, evaporated to dryness, weighed, and their radioactivity determined in a flow counter operated in the Geiger region. Heat inactivated conidia treated in this way gave a count that was never significantly above the background. An attempt was made to use suspensions containing the same number of wild-type and mutant conidia, and in all cases where absolute comparison was desired haemocytometer counts of the suspensions were made.

The addition of nitrogen to a washed conidial suspension causes a large increase in the amount of carbon dioxide fixed by the wild-type, but has only a small effect on carbon dioxide fixation by the suc or at suc strains (Table 10). As little as $0.1 \mathrm{mg}$. of $\mathrm{N}$ in $2 \cdot 6 \mathrm{ml}$. is clearly effective in increasing the carbon dioxide uptake by the wild-type (Fig. 7). The uptake of carbon dioxide by the wild-type strain is linear in the absence of nitrogen but more irregular in its presence (Fig. 8). Under our conditions the fixation of carbon dioxide is not a linear function of the number of conidia; the ratio of carbon dioxide fixation in the presence and absence of nitrogen is higher when the conidial concentration is low than when this concentration is high.

It was suggested to the author by Dr R. C. Fuller that a significant portion of the total fixed carbon dioxide would be removed by the vigorous washing of the conidia involved in our experiments. We therefore studied the total amount of carbon dioxide fixed by stopping the reaction at the conclusion of the incubation period by the addition of trichloracetic acid (final concentration $10 \%, \mathrm{w} / \mathrm{v})$, and then separating the conidia from the acid soluble fraction by centrifugation after $30 \mathrm{~min}$. at $40-50^{\circ}$. Samples of both fractions were 
evaporated to dryness, weighed and their radioactivity determined. The counts recorded in Table 11 are corrected for self-absorption.

The wild-type fixes about as much carbon dioxide into conidia as into the acid soluble fraction, both in the presence and absence of an ammonium salt.

Table 10. Effect of ammonium nitrogen on the fixation of $\mathrm{NaH}^{14} \mathrm{CO}_{3}$

\begin{tabular}{|c|c|c|c|c|}
\hline \multirow[b]{2}{*}{ Expt. } & \multirow[b]{2}{*}{ Nitrogen } & \multicolumn{3}{|c|}{ Strain } \\
\hline & & $7 \mathbf{A}\left(a t^{+} s u c^{+}\right)$ & $46005(s u c)$ & $86-1(a t s u c)$ \\
\hline 1 & 0 & $\begin{array}{l}384 \\
396\end{array}$ & $\begin{array}{l}163 \\
194\end{array}$ & 369 \\
\hline & + & $\begin{array}{c}2120 \\
1650 \\
\left(5.2 \times 10^{7}\right)\end{array}$ & $\begin{array}{c}217 \\
227 \\
\left(2 \cdot 6 \times 10^{7}\right)\end{array}$ & $\begin{array}{c}362 \\
231 \\
\left(4 \cdot 3 \times 10^{7}\right)\end{array}$ \\
\hline 2 & 0 & $\begin{array}{l}257 \\
425 \\
323\end{array}$ & I & $\begin{array}{l}168 \\
160 \\
109\end{array}$ \\
\hline & + & $\begin{array}{c}1785 \\
1910 \\
1890 \\
\left(6 \cdot 6 \times 10^{7}\right)\end{array}$ & $\begin{array}{l}- \\
\text { - } \\
-\end{array}$ & $\begin{array}{c}245 \\
245 \\
158 \\
\left(4.4 \times 10^{7}\right)\end{array}$ \\
\hline
\end{tabular}

Recorded total counts per minute after $2 \mathrm{hr}$. shaking in $2 \mathrm{ml} .0 \cdot 067 \mathrm{M}-\mathrm{KH}_{2} \mathrm{PO}_{4}-\mathrm{Na}_{2} \mathrm{HPO}_{4}$ buffer pH 6.0 with $2 \%$ sucrose and $0.05 \% \mathrm{MgSO}_{4} .7 \mathrm{H}_{2} \mathrm{O}$ plus $0 \cdot 2 \mathrm{ml}$. $\mathrm{NaH}^{14} \mathrm{CO}_{3}$ solution containing $1 \mu \mathrm{c} .{ }^{14} \mathrm{C} / 25 \mathrm{mg} . \mathrm{NaHCO}_{3} / \mathrm{ml}$.

Values in parentheses indicate number of conidia added (haemocytometer counts). Experiment 1, final washings with hot water. Expt. 2, final washings with hot ethanol.

Manometer vessels shaken $2 \mathrm{hr}$. at $30^{\circ}$ after tipping $\mathrm{NaH}^{14} \mathrm{CO}_{3}$.

Expt. 1, 6-day-old cultures; heat inactivated conidia showed no incorporation. Expt. 2, $\boldsymbol{\gamma}$-day-old cultures; heat inactivated conidia showed no incorporation.

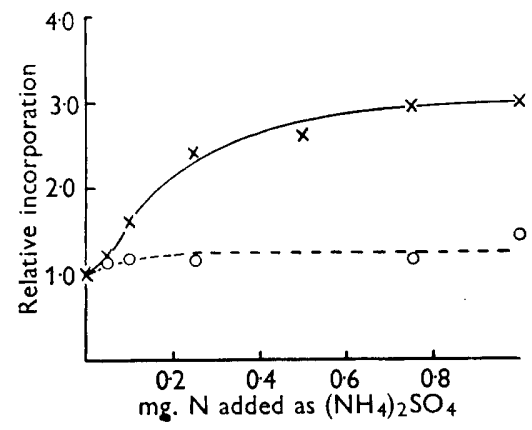

Fig. 7

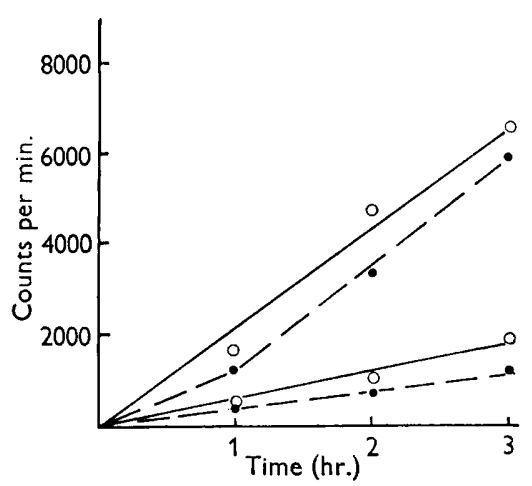

Fig. 8

Fig. 7. Effect of ammonium sulphate nitrogen on the incorporation of $\mathrm{NaH}^{14} \mathrm{CO}_{3}$ by wildtype and suc conidia. Measured incorporation of $\mathrm{NaH}^{14} \mathrm{CO}_{3}$ as total c.p.m. after $2 \mathrm{hr}$. Ammonium sulphate added to $2.0 \mathrm{ml}$. conidial suspension in buffer $(0.067 \mathrm{M}-$ $\mathrm{KH}_{2} \mathrm{PO}_{4}-\mathrm{Na}_{2} \mathrm{HPO}_{4} \mathrm{pH} 6 \cdot 0+2 \%$ sucrose $+0.05 \% \mathrm{MgSO}_{4} \cdot 7 \mathrm{H}_{2} \mathrm{O}$ ) plus $0 \cdot 2 \mathrm{ml}$. $\mathrm{NaH}^{14} \mathrm{CO}_{3}$ containing $1 \mu \mathrm{c} .{ }^{14} \mathrm{C} / 25 \mathrm{mg}$. $\mathrm{NaHCO}_{3} / \mathrm{ml} . \quad \times$, suc ${ }^{+}$; $\bigcirc$, suc.

Fig. 8. Incorporation of $\mathrm{NaH}^{14} \mathrm{CO}_{3}$ by wild-type conidia as a function of time, conidial concentration and the presence of nitrogen. Dotted curve, $1 \mathrm{ml}$. conidial suspension; solid curve, $2 \mathrm{ml}$. conidial suspension. Top curve of each in the presence of $0.5 \mathrm{mg}$. of nitrogen as $\left(\mathrm{NH}_{4}\right)_{2} \mathrm{SO}_{4}$. 
The striking feature of this experiment, however, is the effect of ammonium salts in increasing the amount of carbon dioxide fixed into the acid soluble fraction of the mutant tested without causing a concomitant increase in the conidial fraction. More recent experiments indicate that the fixed material in the acid soluble fraction is not ether extractable. Succinate, a compound which will permit growth of the suc strains in minimal medium, does not lead to an increase in the amount of carbon dioxide fixed into the conidial fraction, even after $2 \mathrm{hr}$. preincubation of conidia in succinate-containing buffer.*

Table 11. Distribution of the ${ }^{14} \mathrm{CO}_{2}$ fixed by wild-type and at suc conidia

\begin{tabular}{|c|c|c|c|c|c|c|}
\hline & & & & & & \\
\hline & $\begin{array}{r}7 \mathrm{~A} \\
\mathrm{~N}\end{array}$ & $\begin{array}{l}\left.u c^{+}\right) \\
\text {en }\end{array}$ & $\begin{array}{r}86- \\
N\end{array}$ & $\begin{array}{l}s u c) \\
\text { gen }\end{array}$ & $\begin{array}{r}\text { 86-1 } \\
\text { incu } \\
\text { su } \\
\text { N }\end{array}$ & $\begin{array}{l}\text { ec) pre-- } \\
\text { d with } \\
\text { ate } \\
\text { gen }\end{array}$ \\
\hline Fraction & 0 & + & 0 & + & 0 & + \\
\hline Conidia & $\begin{array}{l}1720 \\
1670\end{array}$ & $\begin{array}{l}4900 \\
5280\end{array}$ & $\begin{array}{l}785 \\
710\end{array}$ & $\begin{array}{l}655 \\
711\end{array}$ & $\begin{array}{l}801 \\
819\end{array}$ & $\begin{array}{l}720 \\
712\end{array}$ \\
\hline $\begin{array}{l}\text { Supernatant } \\
\text { (acid-soluble) }\end{array}$ & $\begin{array}{l}2230 \\
1960\end{array}$ & $\begin{array}{l}6880 \\
5280\end{array}$ & $\begin{array}{l}520 \\
545\end{array}$ & $\begin{array}{l}1610 \\
1800\end{array}$ & $\begin{array}{l}570 \\
545\end{array}$ & $\begin{array}{l}2360 \\
2480\end{array}$ \\
\hline
\end{tabular}

Recorded total counts per minute in the various fractions after $2 \mathrm{hr}$. shaking in $2 \mathrm{ml}$. $0.067 \mathrm{M}-\mathrm{KH}_{2} \mathrm{PO}_{4}-\mathrm{Na}_{2} \mathrm{HPO}_{4}$ buffer $\mathrm{pH} 6.0$ with $1 \%$ sucrose and $0.05 \% \mathrm{MgSO}_{4} .7 \mathrm{H}_{2} \mathrm{O}$ plus $0 \cdot 2 \mathrm{ml}$. $\mathrm{NaH}^{14} \mathrm{CO}_{3}$ solution containing $2 \mu \mathrm{c} .{ }^{14} \mathrm{C} / 25 \mathrm{mg}$. $\mathrm{NaHCO}_{3} / \mathrm{ml}$.

Nitrogen added $=0.25 \mathrm{ml}$. of a solution of $\left(\mathrm{NH}_{4}\right)_{2} \mathrm{SO}_{4}$ containing $2 \mathrm{mg}$. N/ml. Succinate added to buffer where indicated $=0.1 \%$ disodium succinate. The conidial concentrations were different for the three strains tested.

\section{DISCUSSION}

The unstable balance (Strauss, 1955 b) between carbohydrate and nitrogen metabolism in the suc mutants is seen: $(a)$ in the inhibitory effect of nitrogen salts on the germination and growth of suc and at suc conidia; $(b)$ in the relationship between the accumulation of $\mathrm{AMC}$ and the presence of ammonium salts; $(c)$ in the lack of increased oxygen uptake in the presence of ammonium salts by mutant conidia compared to the wild-type; and $(d)$ by the relative accumulation of acid-soluble products of carbon dioxide fixation in the presence of ammonium salts by the mutant tested compared to the wild-type. Assuming that the supply of dicarboxylic acid is limiting in the suc mutants (an assumption required by the growth-promoting effects of dicarboxylic acids), addition of nitrogen salts might be expected to compete with $\mathrm{C}_{2}$ fragments for the limited supply of $\mathrm{C}_{4}$ compounds available by forming amino acids or other synthetic products, the nature of which has not yet been established (Fig. 8). Ammonium salts are known to be ketogenic when added to liver slices, and a similar competition for dicarboxylic acids has been suggested by Recknagel $\&$ Potter (1951) to account for this ketogenic effect. In neurospora, when the

* L-asparagine increases the amount of $\mathrm{C}^{14} \mathrm{O}_{2}$ fixed by mutant conidia to almost the wild-type level. 
supply of $\mathrm{C}_{4}$ acids required for $\mathrm{C}_{2}$ oxidation is diminished, products such as pyruvic acid $\alpha$-ketoisovaleric acid and AMC accumulate (Fig. 9).

Notwithstanding the growth-promoting action of intermediate compounds of the tricarboxylic acid cycle, it seems likely that the suc and at suc strains make the same use of the tricarboxylic acid cycle for acetate oxidation as does the wild-type (Strauss, 1955 a). Both suc and at suc strains oxidize acetate as well as the wild-type, even though the at suc strain does not start growth with acetate as a supplement to minimal medium until after a 7-day lag period. Fluoroacetate, which is commonly used as an inhibitor of the tricarboxylic

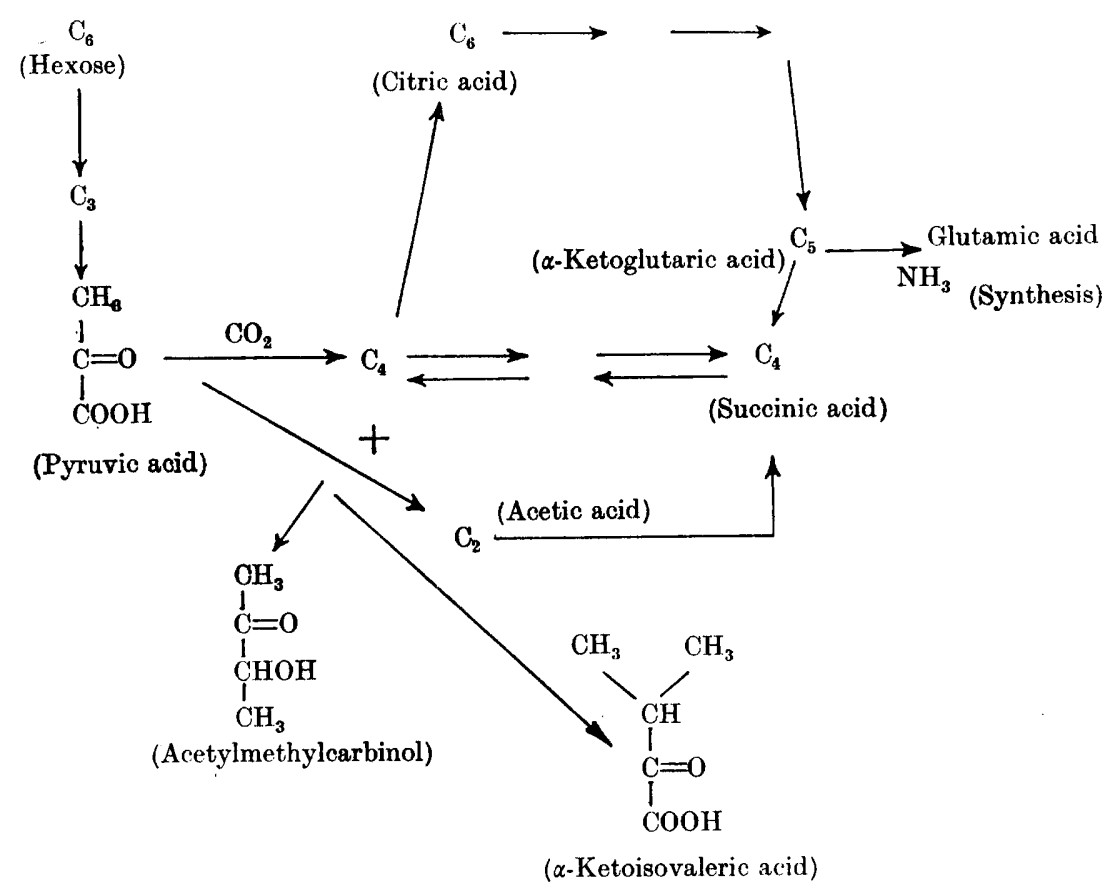

Fig. 9. Scheme of metabolism in the suc and at suc mutants of Neurospora crassa.

acid cycle (Peters, 1952), inhibits acetate oxidation by both wild-type and suc strains, and this inhibition is accompanied by an accumulation of citrate indicating that citrate is an intermediate in acetate oxidation by the suc mutants of Neurospora. Other mutants (of Escherichia coli) requiring dicarboxylic acids for growth and not responding to acetate have been described (Gilvarg \& Davis, 1954), but there is presumably no use made of the tricarboxylic acid cycle in these strains since they are unable to oxidize acetate and lack condensing enzyme. Non-utilization of acetate for growth by strains requiring dicarboxylic acids, however, does not preclude use of the tricarboxylic acid cycle as a mechanism of acetate oxidation.

Pyruvic acid, $\mathrm{AMC}$ and $\mathrm{C}_{2}$ condensation products which do not require complete oxidation accumulate in cultures of the suc mutants (necessarily grown in the presence of nitrogen salts) because of the deficiency in the dicarboxylic acid catalyst required for $\mathrm{C}_{2}$ fragment oxidation. The same 
accumulation products are produced in the suc mutants, where there is no immediate block to pyruvate oxidation as in the $a c$ mutants (Strauss \& Pierog, 1954), where there is a block in the oxidation of pyruvate: another illustration of the danger of using accumulations as evidence of genetic block (Adelberg, 1953). The relationship between succinate, a growth requirement, and AMC, a by-product of a true intermediate, is another case in which an end product controls the accumulation of a precursor (Strauss, 1955 $a, b$; Adelberg \& Umbarger, 1953). In this case, however, the 'end product' (succinate) is a catalyst for the metabolism of the intermediate.

At present it is not possible for the author to give an adequate explanation for the dicarboxylic acid deficiency of the suc mutants or to locate an absolute 'genetic block' in these strains. The tricarboxylic acid cycle operating in a complete cycle regenerates 1 mole of dicarboxylic acid for every mole supplied. Therefore, some other mechanism must be present to insure a net increase in the amount of dicarboxylic acids in an organism using the cycle for energy liberation and for the production of intermediates (Abelson \& Vogel, 1955). At least two possible alternate mechanisms exist for the synthesis of $\mathrm{C}_{4}$ acids; carbon dioxide fixation in $\mathrm{a}_{3}+\mathrm{C}_{1}$ type of condensation (Utter \& Wood, 1951), and a $\mathrm{C}_{2}+\mathrm{C}_{2}$ condensation by the Wieland-Thunberg reaction (Seaman \& Naschke, 1955). However, the suc mutants are able to fix carbon dioxide, and the amount of carbon dioxide fixed in the acid-soluble fraction is increased on the addition of ammonium salts. The deficiency in the suc mutants is apparently in the incorporation of the fixation products into the non-soluble fraction (protein?), but this is what might be expected in any strain unable to grow.

A deficiency in the Wieland-Thunberg condensation might logically be expected in the at strain because of the lack of response of the at suc strain to acetate. However, Seaman (personal communication) has shown that both wild-type and mutant (at suc) preparations show comparable activities of the reversible succinate-cleaving enzyme.

Investigations in biochemical genetics seem to uncover two types of 'biochemical mutants'; one type showing a fairly simple relationship between gene, enzyme and growth requirement (Fincham, 1954; Davis, 1955), the other requiring a complex interpretation in terms of inhibitors and the balance of reactions (Mitchell \& Mitchell, 1952). The advantage of studies of this latter type is that they show, somewhat more clearly than is possible by studies with the wild-type, the interactions between multi-enzyme systems (Dixon, 1949) which may be the basis for the intracellular regulation of metabolism (Strauss, $1955 b$ ). An effect that is present in 'wild-type' preparations, i.e. the ketogenic effect of ammonium (Recknagel \& Potter, 1951) may be magnified in a mutant until a growth requirement occurs. Study of such mutants permits a more ready identification of the interactions actually regulating metabolism in normal organisms.

The author would like to acknowledge his gratitude for the expert technical assistance of Miss Tiiu Vaharu, and to Dr R. C. Fuller for suggesting the experiment on p. 505. This work was supported under contract AT (30-1) 1138 between Syracuse University and the United States Atomic Energy Commission. 


\section{REFERENCES}

Abelson, P. H. \& Vogel, H. J. (1955). Amino acid biosynthesis in Torulopsis utilis and Neurospora crassa. J. biol. Chem. 213, 355.

ADELBERG, E. A. (1953). The use of metabolically blocked organisms for the analysis of biosynthetic pathways. Bact. Rev. 17, 253.

Adelberg, E. A. \& Umbarger, H. E. (1953). Isoleucine and valine metabolism in Escherichia coli. V. $\alpha$-Keto-isovaleric acid accumulation. J. biol. Chem. 205, 475.

Barratt, R. W., Newmeyer, D., Perkins, D. D. \& Garnjobst, L. (1954). Map construction in Neurospora crassa. Advanc. Genet. 5, 1.

Beadle, G. W. \& TAtum, E. L. (1945). Neurospora. II. Methods of producing and detecting mutations concerned with nutritional requirements. Amer.J. Bot. 32, 678.

Davis, B. D. (1955). Nutritional and enzymatic studies on microbial mutants. In Perspectives and Horizons in Microbiology, p. 40. Ed. S. A. Waksman. New Brunswick, N.J.: Rutgers University Press.

Drxon, M. (1949). Multi-Enzyme Systems. Cambridge: University Press.

DubEs, G. R. (1953). Investigations of some 'unknown' mutants of Neurospora crassa. Ph.D. Thesis, California Institute of Technology.

Ettinger, R. H., Goldbaum, L. R. \& Smith, L. H., Jun. (1952). A simplified photometric method for the determination of citric acid in biological fluids. J. biol. Chem. 199, 531.

Fincham, J. R. S. (1954). Effects of a gene mutation in Neurospora crassa relating to glutamic-dehydrogenase formation. J. gen. Microbiol. $11,236$.

Gilvarg, C. \& Davis, B. D. (1954). Significance of the tricarboxylic acid cycle in Escherichia coli. Fed. Proc. 13, 217.

Krebs, H. A., Gurin, S. \& Eggleston, L. V. (1952). The pathway of oxidation of acetate in baker's yeast. Biochem. $J .51,614$.

LEwIs, R. W. (1948). Mutants of Neurospora requiring succinic acid or a biochemically related acid for growth. Amer. J. Bot. 35, 292.

Mitchell, M. B. \& Mitchell, H. K. (1952). Observations on the behavior of suppressors in Neurospora. Proc. nat. Acad. Sci., Wash. 38, 205.

Peters, R. A. (1952). Lethal synthesis. Proc. roy. Soc. B, 139, 143.

Recknaged, R. O. \& Potter, V. R. (1951). Mechanism of the ketogenic effect of ammonium chloride. J. biol Chem. 191, 263.

Seaman, G. R. \& Naschke, M. D. (1955). Reversible cleavage of succinate by extracts of Tetrahymena. J. biol. Chem. 217, 1.

Strauss, B. S. (1953). The accumulation of acetylmethylcarbinol (3-hydroxy-2butanone) by acetate-requiring mutants of Neurospora crassa. J. Amer. chem. Soc. 75, 1012.

Strauss, B. S. $(1955 a)$. Studies on the metabolism of acetate by acetate-requiring mutants of Neurospora crassa. Arch. Biochem. Biophys. 55, 77.

Strauss, B. S. (1955b). A mechanism of gene interaction. Amer. Nat. 89, 141.

Strauss, B. S. \& Pierog, S. (1954). Gene interactions: The mode of action of the suppressor of acetate-requiring mutants of Neurospora crassa. J.gen. Microbiol. $10,221$.

Utter, M. F. \& Wood, H. G. (1951). Mechanisms of fixation of carbon dioxide by heterotrophs and autotrophs. Advanc. Enzymol. 12, 41.

WESTERFELD, W. W. (1945). A colorimetric determination of blood acetoin. J. biol. Chem. 161, 495.

Woodward, V. W. (1954). Mutation rates at one glutamic acid locus in Neurospora crassa. Rec. Genet. Soc. Amer. 23, 74. 
Woodward, V. W., De Zeeuw, J. R. \& Srb, A. M. (1954). The separation and isolation of particular biochemical mutants of Neurospora by differential germination of conidia, followed by filtration and selective plating. Proc. nat. Acad. Sci., Wash. 40, 192.

Yemm, E. W. \& Folkes, B. F. (1954). The regulation of respiration during the assimilation of nitrogen in Torulopsis utilis. Biochem. J. 57, 495.

(Received 3 June 1955) 